\title{
Construcción del relato informativo audiovisual y su impacto sobre la reputación de la radio y la televisión
}

\section{Audiovisual informative narrative construction and its impact on television and radio reputation}

\author{
Juan-José Perona-Páez; María-Luz Barbeito-Veloso; Alejandra Hernández-Ruiz; \\ Victoria Rodríguez-Prieto
}

Cómo citar este artículo:

Perona-Páez, Juan-José; Barbeito-Veloso, María-Luz; Hernández-Ruiz, Alejandra; Rodríguez-Prieto, Victoria (2020). "Construcción del relato informativo audiovisual y su impacto sobre la reputación de la radio y la televisión". Profesional de la información, v. 29, n. 6, e290634.

https://doi.org/10.3145/epi.2020.nov.34

Artículo recibido el 17-05-2020 Aceptación definitiva: 08-07-2020

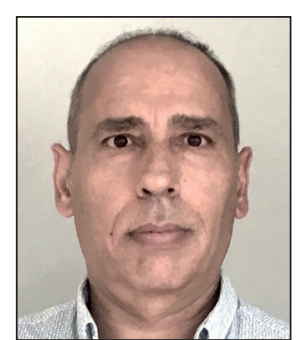

Juan-José Perona-Páez https://orcid.org/0000-0001-8256-9070

Universitat Autònoma de Barcelona Facultat de Ciències de la Comunicació Carrer de la Vinya, s/n. Edifici I 08193 Bellaterra (Barcelona), España juanjose.perona@uab.cat

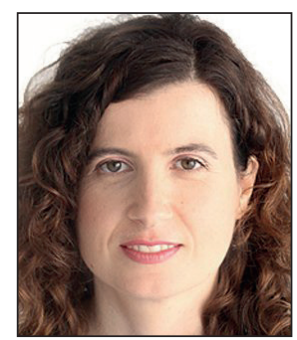

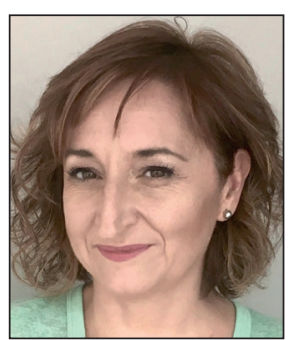

María-Luz Barbeito-Veloso $\square$ https://orcid.org/0000-0002-3159-7423

Universitat Autònoma de Barcelona Facultat de Ciències de la Comunicació Carrer de la Vinya, s/n. Edifici I 08193 Bellaterra (Barcelona), España mariluz.barbeito@uab.cat

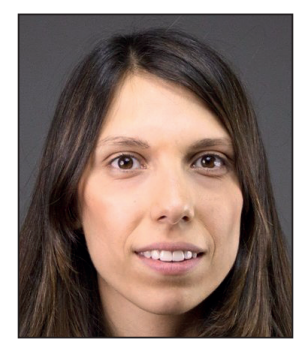

\section{Victoria Rodríguez-Prieto} https://orcid.org/0000-0001-9430-4360

Universidad Nebrija

Facultad de Ciencias Sociales

Santa Cruz de Marcenado, 27

28015 Madrid, España

mrodriguezpr@nebrija.es

\section{Resumen}

Los medios de comunicación, al igual que el resto de las organizaciones, necesitan alcanzar un alto nivel reputacional, por lo que no sólo es importante ofrecer un buen producto o servicio, sino que también es necesario que se perciba como tal y que esto influya positivamente en la imagen de las entidades. El objetivo de este trabajo es comprobar si existen correlaciones entre el contenido informativo que difunden los medios audiovisuales y la reputación que de ellos tienen sus públicos. Partiendo de una configuración del concepto de reputación a partir de variables como la credibilidad, el rigor informativo, la calidad periodística, y la ética y deontología profesional, el estudio se diseñó en dos etapas. En la primera, se envió una encuesta a profesionales de la comunicación y a la audiencia con el fin de conocer la percepción que tienen de los medios en relación con los aspectos citados. En la segunda, se llevó a cabo un análisis de contenido para determinar en qué grado se manifiestan los indicadores que definen esas variables en la producción informativa. Esta investigación compara los resultados de ambas fases, tomando como muestra de análisis las principales cadenas y emisoras generalistas españolas (La primera de TVE, Telecinco, Antena 3 y La sexta, en el caso de la televisión, y COPE, 
Onda cero, RNE y la SER, en el de la radio). Los resultados revelan que existen correspondencias entre las valoraciones que hacen los encuestados y los datos del análisis de contenido, especialmente en el caso de los canales y las emisoras que logran las peores posiciones. El producto informativo contribuye así a la construcción de la reputación de los medios de comunicación, siendo los indicadores que intervienen en el rigor informativo y en la ética y deontología profesional los que consiguen un mayor índice de reciprocidad.

\title{
Palabras clave
}

Reputación; Valores intangibles; Radio; Televisión; Información; Credibilidad; Rigor informativo; Calidad periodística; Ética; Deontología profesional.

\begin{abstract}
Like all entities, media need to achieve a high level of reputation, which requires not only the provision of an excellent product or service but also for it to be perceived as such in order to create a positive image. The aim of this study is to confirm whether there is any correlation between the information content disseminated by audiovisual media and their level of reputation among their audiences. To this end, the notion of reputation is based on variables such as credibility, informative rigor, journalistic quality, professional ethics, and deontology. This study involved two phases. Firstly, we conducted a survey among communication professionals and audiences to determine their perception of media in terms of the aforementioned aspects. Secondly, we carried out a content analysis to gauge the degree to which the indicators that define these variables are present in news production. Finally, the study compares and contrasts the results from both phases. Overall, this case study covers the most important Spanish television channels and generalist radio stations, namely La primera (TVE), Telecinco, Antena 3, and La sexta, as well as COPE, Onda cero, RNE, and SER. The main results reveal correspondences between the assessments made by respondents and the results of the content analysis. In this regard, the channels and broadcasters that achieve the worst positions show greater correspondences. Therefore, it can be concluded that the information product contributes to the construction of media's reputation, where the indicators play a key role, with informative rigor, professional ethics, and deontology being those that achieve the highest rate of reciprocity.
\end{abstract}

\section{Keywords}

Reputation; Intangible values; Radio; Television; Information; Credibility; Informative rigor; Journalistic quality; Ethics; Professional deontology.

\section{Introducción}

La gestión de los valores intangibles se perfila como una de las estrategias que las organizaciones anteponen a otras con el fin de buscar vías de diferenciación en un mercado cada vez más homogéneo, competitivo y atomizado. Los medios de comunicación no son ajenos a esta tendencia, por lo que las corporaciones mediáticas necesitan generar percepciones positivas, no solo entre su audiencia, sino también entre sus accionistas y trabajadores. Esta circunstancia explica que, con el objetivo de mejorar su posicionamiento, las acciones comunicativas de las empresas y las instituciones se orienten con mayor frecuencia hacia la marca y

"estén dejando de apoyarse exclusivamente en el producto" (Carrillo; Castillo-Díaz; Tato-Jiménez, 2008, p. 239),

sobre todo en cuanto a la difusión de sus atributos físicos se refiere. En este contexto, la transmisión de lo inmaterial crece enormemente y lo hace mediante la exploración de las nuevas formas de conexión con los públicos que ofrecen desde las técnicas más avanzadas del marketing experiencial (Moral; Fernández-Alles, 2012; Manzano et al., 2012; Hultén; Broweus; Van-Dijk, 2009; Lenderman; Sánchez, 2008) hasta las nuevas dinámicas publicitarias y de relaciones públicas que redundan tanto en la construcción de identidad e imagen corporativas (Barbeito-Veloso; Perona-Páez, 2019) como en la arquitectura global de la buena reputación que persiguen compañías y entidades de todo tipo.

El prestigio del que goza algo o alguien es probablemente la manera más entendible de definir la reputación, por lo que es comprensible que en la comunicación empresarial e institucional se le adjudique un valor estratégico de primer orden. Villafañe (2004, p. 31) sostiene que:

“la reputación es la cristalización de la imagen corporativa de una organización cuando esta es el resultado de un comportamiento corporativo excelente, mantenido a lo largo del tiempo, que le confiere un carácter estructural ante sus stakeholders estratégicos".

A la luz de esta conceptualización, parece claro que son los grupos de interés -entre los que se cuentan clientes, inversores, proveedores y competidores- quienes determinan la reputación de una organización a partir de la experiencia acumulada que tienen en su relación con la misma. De-la-Fuente-Sabaté y De-Quevedo-Puente (2003) otorgan incluso el estatus de "contrato" a esa relación, en sintonía con las apreciaciones de Jensen y Meckling (1976), Cornell y Shapiro (1987) y Hill y Jones (1992). Todos ellos conciben la reputación corporativa como una "garantía contractual" que se define por lo que los públicos esperan de las prácticas que desarrolla la entidad con la que interactúan. De este modo, la reputación se verá dañada si la forma de proceder de la corporación es contraria o no se ajusta a las expectativas generadas por un determinado agente. 
Lange et al. (2011) inciden también en la importancia que, en la reputación corporativa, adquiere la relación con los stakeholders. De hecho, estos autores aluden a tres dimensiones que afectan al concepto que nos ocupa:

1) El ser conocido, lo que tiene que ver con la notoriedad de la compañía, aunque sin que ello derive en una opinión sobre su reputación.

2) El ser conocido por algo, lo que estaría relacionado con la capacidad de prever cómo va a actuar la empresa o la institución en relación con un determinado público y sus intereses.

3) La percepción general favorable, materializada en las visiones de un conjunto de agentes sobre una organización concreta.

Por tanto, la reputación corporativa viene determinada por la notoriedad de una organización, por la experiencia y la relación que se han tenido, por lo que se espera en el futuro de dicha organización y por las percepciones sobre el atractivo general de la misma.

Las grandes corporaciones han sido tradicionalmente el epicentro de las investigaciones en torno al objeto de estudio de esta aportación. Sin embargo, en línea con Ortiz-de-Guinea, Villafañe y Caffarel-Serra (2018), la revisión de la bibliografía previa constata que apenas existen trabajos sobre la reputación de los medios de comunicación. Sí se encuentran estudios que evalúan, además de otras instituciones, los medios, especialmente el grado de confianza que la población deposita en ellos. Entre estos estudios destaca el Edelman trust barometer:

https://www.edelman.com/trust/2020-trust-barometer

que en su edición de 2020 revelaba que solo un $47 \%$ de las personas encuestadas a nivel mundial confiaba en los medios -el mismo porcentaje que lograban los gobiernos- mientras que las empresas y las ONGs merecían la confianza del $55 \%$. Sobre la calidad de la información de los medios de comunicación que habitualmente consumían, el 57\% afirmaba que eran indignos de su confianza y el $76 \%$ se mostraba preocupado por las noticias falsas. Este último porcentaje había aumentado en 6 puntos en el periodo 2018-20. La calidad de la información a la que aquí se alude resulta compleja de evaluar, ya que como sostienen Campos-Freire, Soengas-Pérez y Rodríguez-Castro (2018) la mayoría de los indicadores que en ella intervienen se construyen a partir de valores abstractos, especialmente los cualitativos, por lo que es muy difícil establecer unos criterios objetivos que conformen un sistema que permita medirla, como también sucede con el rigor, la pluralidad, la transparencia y su valor social.

La confianza es uno de los tres aspectos a los que se refieren Berens y Van-Riel (2004) para medir la reputación corporativa, cuyas herramientas se usan para verificar el cumplimiento de estándares en determinadas dimensiones, además de considerar otros parámetros relevantes como podrían ser la posesión de reconocimientos o sellos de calidad, la percepción que tienen los clientes o usuarios de las empresas y servicios, o las actividades de responsabilidad social. La sistematización de todos estos indicadores y la oportunidad de observar cómo se manifiestan en el mundo empresarial propició, por ejemplo, el surgimiento de los denominados rankings o monitores de medición, entre los que se cuentan el Reputation Institute y el Monitor Empresarial de Reputación Corporativa (Merco), este último de origen español. El Merco es un instrumento de evaluación reputacional lanzado en el año 2000, basado en un método "multigrupo de interés" compuesto por seis evaluaciones y veinticinco fuentes de información. En 2020, Merco elaboraba ocho monitores (Merco empresas, Merco líderes, Merco responsabilidad y gobierno corporativo, Merco talento, Merco talento universitario, Merco consumo, Merco digital y Monitor de reputación sanitaria) y tenía presencia en once países: España, Colombia, Argentina, Chile, Ecuador, Bolivia, Brasil, México, Perú, Costa Rica y Panamá.

La reputación de un medio de comunicación obedece al comportamiento en relación con su realidad periodística y empresarial y al reconocimiento de sus públicos

De cualquier forma, parece lógico pensar que los aspectos que condicionan la reputación corporativa son aplicables a los medios de comunicación, sobre todo a aquellos que actúan como entes informativos de importante calado social. A juicio de Ortiz-de Guinea, Villafañe y Caffarel-Serra (2018) la reputación, en este caso, se erigiría en un binomio que incluye, por una parte, el comportamiento de cada medio en relación con su realidad periodística y empresarial y, por otra, el reconocimiento, es decir, la valoración que sus públicos hacen de esa realidad y del desempeño periodístico y empresarial en función de la satisfacción de sus expectativas con relación a dicho medio. Esta visión entronca con la que a mediados de la década de los 50 del pasado siglo ya tenían Carl Hovland, Irving Janis y Harold Kelley, quienes, según recogen Calvo-Porral; Martínez-Fernández y Juanatey-Boga (2014, p. 301):

"definieron la credibilidad de una marca o producto, en este caso un medio de comunicación, como la percepción del consumidor de su veracidad, confianza, buena voluntad y también de su experiencia".

Con independencia del tipo de medio -prensa, radio, televisión, etc.-, la confianza que en ellos se deposita proviene básicamente de la credibilidad que la audiencia, uno de sus públicos externos esenciales, otorga a sus contenidos informativos. La credibilidad de la información, foco de interés de la mass communication research norteamericana desde mediados del siglo XX, es probablemente uno de los intangibles más estudiados, especialmente desde la perspectiva de los receptores (Yamamoto; Nah, 2018; Metzger et al., 2003; Newhagen; Nass, 1989; Gaziano; McGrath, 1986) y 
la percepción que estos agentes tienen de una propiedad que, sin embargo, "se le concede genéricamente al emisor" (Diezhandino-Nieto; Montiel-Jiménez; Marinas-Herreras, 2007, p. 227).

"De acuerdo con la mayor parte de las investigaciones, la credibilidad se concibe como el resultado de un proceso en el que el individuo examina y evalúa subjetivamente las cualidades de un emisor, contenido, fuente o cualquier otra instancia informativa. Es decir, se entiende como una variable actitudinal, resultado de un proceso cognitivo" (Roses; Gómez-Calderón, 2015, p. 433).

La abundancia de estudios sobre esta cuestión se ha traducido en trabajos amparados en métodos dispares y en una marcada heterogeneidad de los valores y los indicadores utilizados para evaluarla (Balsebre, 1994). Entre esos valores se encuentran, por ejemplo, la veracidad, la objetividad, la imparcialidad, la transparencia, la calidad, la originalidad o la pluralidad informativas -aspectos no exentos de complejidad en su definición-, a los que se unen otros como la libertad, la independencia, la deontología o la ecuanimidad profesionales. En una revisión sobre cómo ha sido analizada la credibilidad en el marco de las ciencias de la comunicación, Roses y Farias-Batlle (2012, p. 81) recogen, entre otras, la siguiente acepción:

"el resultado de la evaluación de la veracidad, precisión, independencia, imparcialidad, confianza, facilidad de uso, completitud de contenido, fiabilidad, y atractivo del medio y/ o de las noticias o de la cobertura específica de un tema".

La confianza y la credibilidad también han sido abordadas desde la óptica de la titularidad de los medios, lo que se ha traducido en trabajos que han centrado su interés en examinar las correlaciones existentes entre estos aspectos y el carácter público o privado de las emisoras de radio y las cadenas de televisión. En una investigación cross-cultural sobre las variables micro y macro que influyen en la confianza, Tsfati y Ariely (2014) observan, tras analizar los ecosistemas comunicativos de 44 países, que en las sociedades democráticas los ciudadanos son más proclives a valorar positivamente la televisión pública que en aquellas gobernadas por regímenes que ejercen un alto control sobre la misma. Otros estudios, como el de Newman y Fletcher (2017), constatan que la propiedad y los intereses comerciales implícitos figuran entre las razones principales para recelar de los medios, por lo que a los de titularidad pública se les conferiría, de entrada, un mayor grado de credibilidad y confianza.

Siguiendo la línea de las investigaciones citadas, en el caso español La primera (TVE) y Radio nacional de España (RNE) partirían, en principio, de una posición más aventajada que las cadenas y las emisoras privadas. Vila-López, Küster-Boluda y Bigné-Alcañiz (2012), en su trabajo comparativo entre la televisión pública y privada en España, ya constataron que la calidad percibida -la que se define a partir de las experiencias que los públicos de interés tienen en relación con una determinada marca- y la identidad visual, es decir, el simbolismo y cualquier otra forma de comunicación que permita transmitir visualmente información de marca, son dos factores en los que sobresale La primera (TVE) sobre las cadenas privadas de manera positiva y significativa. Además del canal público, se analizaron los conceptos de calidad, identidad visual y reputación en Antena 3, Cuatro, Telecinco y La sexta. Los resultados mostraron, entre otras conclusiones, que, para la audiencia, la cadena pública estaba mejor posicionada frente a las privadas en cuestiones como la pluralidad de audiencias atendidas, la pluralidad de géneros programáticos (entretenimiento, ocio, educación, informativos etc.), el respeto a la pluralidad de creencias, los informativos de calidad, la divulgación de la cultura nacional o el cumplimiento de la normativa publicitaria. Por su parte, las privadas solo superaban a la pública en lo relativo a innovación, en tanto que intentaban no repetir fórmulas programáticas y apostaban por sorprender a los espectadores.

En relación con la radio pública, un exhaustivo análisis de contenido realizado por Armand Balsebre en 1994 ya revelaba que los informativos de Radio 1 (RNE) ofrecían:

"una imagen de mayor seguridad y corrección verbal en el trabajo de sus locutores-periodistas, con una performance más correcta, sin interrupciones ni errores técnicos, y un trabajo más riguroso en la redacción de las noticias. Desde esta perspectiva, los informativos de Radio 1 de la muestra analizada definen un nivel mayor de profesionalidad y, por tanto, de credibilidad. Justo en la posición contraria, y siempre desde la perspectiva citada, localizamos a los informativos de la Cadena COPE, y, en una posición intermedia, a los informativos de la Cadena SER (Balsebre, 1994, p. 109).

Junto con las contribuciones académicas, también han proliferado a escala internacional barómetros y estudios de opinión pública que miden el índice de credibilidad de medios y periodistas, como el Eurobarometer del Parlamento Europeo. En España destacan el barómetro del Centro de Investigaciones Sociológicas (CIS), el Informe anual de la profesión periodística de la Asociación de la Prensa de Madrid (APM) y la encuesta GIPEyOP sobre medios y comunicadores de la Universitat de València. No obstante,

"no hay un estudio que analice el reconocimiento y la satisfacción de las expectativas de los grupos de interés de un medio de comunicación" (Ortiz-de-Guinea; Villafañe; Caffarel-Serra, 2018, p. 850).

Pese a que esta aportación se centra en aspectos periodísticos, los autores que se acaban de referenciar sostienen, como ya avanzaba en otra aportación Ortiz-de-Guinea (2015), que en la reputación de un medio de comunicación también interviene la dimensión empresarial como una parte consustancial al buen desempeño que, sobre todo, garantice su sostenibilidad económica. Esta perspectiva es relevante si se atiende a la crisis que anida en el sector desde hace más 
de una década, que afecta, sobre todo, a los medios clásicos. Entre sus causas, se alude a menudo a las transformaciones derivadas de la digitalización de las redacciones, que ha supuesto un replanteamiento de las rutinas productivas, pero también a la pérdida de ciertos valores periodísticos y a los cambios experimentados en el uso y consumo de la información tras la irrupción masiva de internet y de las redes sociales como canales alternativos. A estas posibles causas se suman otras dos importantes: la crisis económica iniciada en 2008, y el cambio de modelo de negocio de los medios tradicionales que tuvo lugar durante los primeros compases de este siglo. Todas estas circunstancias han podido afectar a la calidad del servicio ofrecido por los medios y a su imagen, por lo que subsistir en un contexto adverso les impulsa a fomentar su reputación y cuidar otros intangibles corporativos. El interés de las empresas de comunicación radica ahora, junto con su balance económico, en el refuerzo de sus activos inmateriales.

\section{Objeto de estudio, método y preguntas de investigación}

Este trabajo evalúa el grado de correlación que existe entre el nivel de reputación que se otorga a los medios de comunicación, en este caso cadenas de televisión y emisoras de radio, y los productos informativos que elaboran sus profesionales en el ejercicio de su actividad. La intención es observar si la construcción del relato de la actualidad que hacen los medios audiovisuales coincide con la percepción que tienen los públicos de interés.

La investigación se inició con una propuesta del concepto de reputación, a partir del establecimiento de variables e indicadores específicos, que se ajustara al contexto de los medios de comunicación y que tuviera como objetivo transformar en objeto medible este bien intangible. Una vez fijados los parámetros del análisis reputacional, se ejecutaron dos fases de trabajo:

En la primera, para conocer las percepciones de los públicos, se diseñaron dos encuestas, una que se administró a 135 profesionales del sector de la información en España ${ }^{1}$ y otra a 1.000 personas pertenecientes a la "población informada", es decir, mayores de edad con estudios universitarios trabajando o en búsqueda activa de empleo, que se informen por prensa, televisión o radio al menos 2 o 3 veces por semana². El propósito era disponer de una clasificación de la reputación de los medios a partir de la valoración que de ellos hicieran los encuestados, atendiendo a variables tanto profesionales (credibilidad, rigor informativo, calidad periodística, ética y deontología profesional, independencia y contribución a la democracia) como empresariales (sostenibilidad económica, transparencia en la gestión empresarial, responsabilidad de la propiedad y derechos y deberes de los trabajadores).

En la segunda fase se diseñó un análisis de contenido, en el que se consideraron únicamente las dimensiones profesionales, para observar su comportamiento en las piezas informativas emitidas por los medios audiovisuales de la muestra: La primera (TVE), Telecinco, Antena 3 y La sexta, en el caso de la televisión, y la COPE, Onda cero radio, Radio nacional de España $(R N E)$ y la Cadena SER, en el de la radio. Se descartaron "independencia" y "contribución a la democracia" al no identificarse parámetros cuantificables y considerarse que no eran pertinentes para los contenidos que se iban a estudiar. A cada variable se le asignaron indicadores, algunos transversales, para dotarlas de entidad multidimensional. La relación de indicadores se fijó en función de los utilizados en buena parte de las referencias manejadas en la introducción a este trabajo y en el estudio sobre la credibilidad periodística en la era digital de Hayes, Singer y Ceppos (2007):

\section{Credibilidad:}

- Número de fuentes.

- Acceso a las fuentes.

- Uso de fuentes propias.

- Distinción entre información y opinión.

- Autoría de las piezas.

- Autoría de las imágenes (en el caso de la televisión).

- Actualidad-inmediatez.

- Diversidad de géneros periodísticos.

2. Rigor informativo:

- Origen de la información.

- Estructura de la información.

- Profesionales que intervienen en la elaboración de las piezas.

- Presencia de actores no periodísticos.

- Localización de la información.

- Número de fuentes.

- Diversidad de géneros periodísticos. 
3. Calidad periodística:

- Cantidad de información/piezas.

- Enfoque de las piezas.

- Criterios de noticiabilidad.

- Número de fuentes.

- Autoría de las piezas.

- Autoría de las imágenes (en el caso de la televisión).

- Actualidad-inmediatez.

- Diversidad de géneros periodísticos.

- Origen de la información.

- Estructura de la información.

- Profesionales que intervienen en la elaboración de las piezas.

- Presencia de actores no periodísticos.

4. Ética y deontología profesional:

- Rectificación.

- Paridad en el uso de actores no periodísticos.

- Distinción entre información y opinión.

Para la obtención de la muestra se decidió un evento que favoreciera la homogeneización de los contenidos y evitar así que la diversidad de la agenda de los medios propiciara distorsiones. En televisión, fue la campaña electoral de los comicios generales celebrados en España en noviembre de 2019, mientras que en radio se escogió el proceso de investidura a la presidencia del gobierno español de enero de 2020. La intención inicial era replicar la muestra en radio y en televisión, pero el ataque de un virus informático sufrido por la Cadena SER el 4 de noviembre de 2019:

https://cadenaser.com/ser/2019/11/04/sociedad/1572862102_968725.html

impidió acceder al archivo sonoro de la emisora y, por tanto, resultó imposible recuperar todas las piezas necesarias para completar la selección requerida. Esta es la razón que explica que, en el caso de la radio, se cambiara el criterio de recopilación de unidades para el análisis, aunque siempre con el objetivo de que ambos contenidos estuvieran relacionados. En los dos casos se consideró la multiperspectiva desde la que se pueden abordar los acontecimientos noticiosos.

La recogida de información se organizó en tres momentos, coincidiendo con el inicio, mitad y final de cada uno de los eventos. Siguiendo este criterio, se seleccionaron los informativos vespertinos de La primera (TVE), Telecinco, Antena 3 y La sexta de los días 2, 5 y 8 de noviembre de 2019 (campaña electoral) y los primeros tramos -de 20.00h a 21.00h- de los de la COPE (La linterna), Onda cero radio (La brújula), RNE (24 horas) y Cadena SER (Hora 25) de los días 3, 6 y 7 de enero de 2020 (investidura). La muestra final -compuesta por todas las piezas detectadas sobre las temáticas expuestasla forman 109 unidades de análisis -69 para la televisión y 40 para la radio-, distribuidas como se detalla en la tabla 1.

Tabla 1. Distribución de las unidades de análisis (piezas) por cadenas de televisión y emisoras de radio

\begin{tabular}{|c|c|c|c|c|}
\hline Cadena & Inicio de campaña & Mitad de campaña & Fin de campaña & Total piezas \\
\hline La primera (TVE) & 4 & 5 & 9 & 18 \\
\hline Telecinco & 8 & 1 & 2 & 11 \\
\hline Antena 3 & 4 & 5 & 6 & 15 \\
\hline La sexta & 10 & 8 & 7 & 25 \\
\hline Total & 26 & 19 & 24 & 69 \\
\hline Emisora & $\begin{array}{l}\text { Víspera debate de } \\
\text { investidura }\end{array}$ & $\begin{array}{l}\text { Víspera jornada de } \\
\text { investidura }\end{array}$ & $\begin{array}{l}\text { Jornada de investi- } \\
\text { dura }\end{array}$ & Total piezas \\
\hline COPE & 1 & 3 & 3 & 7 \\
\hline Onda cero radio & 1 & 1 & 8 & 10 \\
\hline Radio nacional de España & 4 & 3 & 5 & 12 \\
\hline Cadena SER & 4 & 2 & 5 & 11 \\
\hline Total & 10 & 9 & 21 & 40 \\
\hline
\end{tabular}

Para observar el comportamiento de los indicadores que definen las cuatro variables de estudio en las 109 piezas localizadas, se diseñó una plantilla que permitiera extraer información, cuantitativa y cualitativa, sobre los aspectos comunes ${ }^{3}$ y específicos que se exponen a continuación:

\section{Aspectos comunes}

1. Tipo de pieza (género).

2. Autoría de la pieza (identificada/no identificada).

3. Número de fuentes utilizadas. 
4. Acceso a las fuentes (especificado/no especificado).

5. Tipo de fuentes, según la clasificación del Centro de Investigaciones Sociológicas (CIS).

6. Tema principal de la pieza.

7. Enfoque de la pieza (positivo, negativo, neutro).

8. Descripción del enfoque.

9. Distinción entre información y opinión (sí/no).

10. Rectificación (sí/no).

11. Actores periodísticos que intervienen en la pieza (conductor, redactor, corresponsal, etc.).

12. Actores no periodísticos.

12.1. Número.

12.2. Identificación (nombre y sexo de los actores que aparecen en las tres primeras posiciones, los cuales se clasifican como actor 1 , actor 2 y actor 3 ).

12.3. Enfoque de los actores.

13. Origen de la información (mencionado/no mencionado).

14. Actualidad (hoy, ayer, hace dos días, etc.).

15. Localización (comunidad autónoma, ciudad, localidad, etc.).

16. Criterios de noticiabilidad (según Warren, 1979).

\section{Aspectos específicos}

- Identificativos (día de emisión, cadena de televisión/emisora de radio y duración de la pieza).

- Estructurales, tales como uso del lenguaje audiovisual, disposición de las unidades de análisis en el informativo, aparición en sumario, composición narrativa de las piezas o, en televisión, incorporación de imágenes propias.

En función del objetivo fijado, que como se ha dicho consiste en evaluar la correlación que existe entre el nivel de reputación que se atribuye a los medios de comunicación y los productos informativos que estos elaboran en el ejercicio de su actividad profesional, la investigación quiere responder a la siguiente pregunta:

- ¿Los medios mejor situados tras el análisis de contenido son los que alcanzan una mejor posición en el ranking de reputación de los profesionales y de la población informada?

En relación con los contenidos informativos y la imagen que tienen los encuestados:

- ¿Dónde hay una mayor correspondencia, entre el sector de los profesionales o entre la población informada?

- ¿Dónde se localiza una mayor coherencia entre los productos informativos y la percepción que se tiene de ellos, en la radio o en la televisión?

- ¿En qué dimensiones profesionales se posicionan los medios públicos frente a los privados según los resultados del análisis de contenido?

\section{Resultados}

\subsection{Credibilidad}

Esta variable se articula en torno a siete indicadores para la radio y ocho para la televisión. Los datos recogidos para cada uno permiten elaborar un ranking en el que Antena 3, por un lado, y la $S E R$, junto con $R N E$, por otro, se sitúan en las posiciones más altas (tabla 3). Por el contrario, La primera (TVE), aunque con un escaso margen con respecto a Telecinco, y la COPE ocupan los últimos lugares. Para establecer esta clasificación se ha determinado el puesto que logra cada medio en cada ítem. En general, se observa que las emisoras de radio que obtienen mejores resultados $-S E R$ y $R N E-$ trabajan con un mayor número de fuentes y son las que más distinguen entre información y opinión en su informativo vespertino. En televisión, la cadena mejor posicionada -Antena 3- es la que utiliza más fuentes, la que atribuye en mayor medida autoría a sus piezas y la que presenta más variedad de géneros informativos.

En número de fuentes, Antena 3 encabeza el ranking, al ser la que utiliza más de tres en el 73,3\% de sus informaciones, es decir, en 11 de sus 15 entregas. En La sexta, el uso de más tres fuentes se manifiesta en el 64\% de las piezas (16) y en La primera (TVE) lo hace en el $44,4 \%$ (8). Por el contrario, en Telecinco imperan las noticias con una sola fuente $(45,5 \%)$, mientras que las que incluyen más de tres representan solo el $27,3 \%$ (3). En radio, el medio que maneja más fuentes en sus contenidos informativos es $R N E$,

En el análisis de contenido, el sector público destaca en ética y deontología profesional siendo la única emisora que, al menos en dos de sus piezas (16,7\%), cuenta con tres o más. En la COPE son mayoritarias las piezas que incorporan una sola fuente $(60 \%)$ y en Onda cero $(50 \%)$ y la SER $(45,5 \%)$ la mitad de las informaciones contienen una única fuente y la otra mitad dos.

Sobre el acceso a las fuentes (eventos, declaraciones, etc.), La sexta es la cadena que con más frecuencia lo especifica, puesto que lo hace en 23 (92\%) de sus 25 entregas dedicadas a la campaña electoral de noviembre de 2019. Telecinco identifica el acceso en 10 (90,9\%), mientras que La primera (TVE) y Antena 3 dejan alrededor de un 20\% de sus informaciones sin concretar cómo se ha accedido a las fuentes que utilizan (22,2\% y $20 \%$ respectivamente). En radio, Onda cero y la COPE lo especifican en el $100 \%$ de sus piezas, mientras que $R N E$ lo hace en el $91,7 \%$ y la SER en el $63,6 \%$. En todos 
los casos, como consecuencia de las temáticas seleccionadas, predominan las fuentes que el Centro de Investigaciones Sociológicas (CIS) califica como "Instituciones I", entre las que se encuentran los partidos políticos. Tanto en radio como en televisión, el uso de este tipo de fuentes se da en cerca del $70 \%$ de las unidades analizadas.

Por lo que se refiere al uso de fuentes propias es, porcentualmente, más abundante en Telecinco, en tanto que aparecen en 5 ocasiones (45,5\%). En este indicador, La primera (TVE) ostenta el segundo lugar, ya que las incluye en 8 (44,4\%) de las unidades de análisis, mientras que Antena 3, que las incorpora en 3 piezas sobre 15 (20\%) y La sexta, en 5 sobre 25 (20\%), empatan en una posición inferior. En radio, las fuentes propias son utilizadas por la SER en el 36,4\% de las ocasiones, es decir, en 4 de las 11 informaciones dedicadas al proceso de investidura de enero de 2020. A ella le sigue RNE, con inclusión de fuentes propias en dos de sus piezas. Sorprende que, a diferencia de sus competidoras, Onda cero y la COPE no utilicen fuentes propias, y que, en cambio, esta última emisora recurra habitualmente a especialistas/expertos que trabajan para otros medios como El confidencial.

En televisión se percibe que es muy significativa la información cuya autoría no se identifica, hasta el punto de que en Antena 3 no se hace en el 40\% de los casos, en La sexta en el 64\%, en La primera (TVE) en el 66,6\% y en Telecinco en el $90,9 \%$. Esta tendencia se observa también al identificar la autoría de las imágenes que ilustran las noticias o los reportajes, aunque en general todas las cadenas mejoran notablemente sus posiciones (tabla 2).

Tabla 2. Televisión: autoría de las imágenes por piezas y cadenas (entre paréntesis, datos en \% sobre el total de cada cadena)

\begin{tabular}{|l|c|c|c|}
\hline Autoría de las imágenes & $\begin{array}{c}\text { La primera } \\
(\text { TVE) }\end{array}$ & Telecinco & Antena 3 \\
\hline Imágenes propias & $6(33,3)$ & 0 & $3(20,0)$ \\
\hline Combinación de imágenes propias con otras no identificadas & $4(22,2)$ & $5(45,5)$ & $7(46,7)$ \\
\hline Imágenes proporcionadas por la audiencia (redes sociales, plataformas, etc.) & $1(5,6)$ & 0 & 0 \\
\hline Otras & 0 & $1(9,1)$ & $3(20,0)$ \\
\hline No se identifica la autoría de las imágenes & $7(38,9)$ & $5(45,5)$ & $2(13,3)$ \\
\hline Total cadena & 18 & 11 & $15(12,0)$ \\
\hline
\end{tabular}

En la información radiofónica es difícil establecer la autoría de las piezas, en tanto que la única opción posible es atribuirla a la voz que difunde la información, es decir, a la figura periodística (conductor del informativo, redactor, experto/ analista, etc.) que interviene en cada momento. Partiendo de esta premisa, en el $100 \%$ de los casos analizados la autoría quedaría atribuida.

A la hora de distinguir entre información y opinión, en los informativos televisivos no se observan discrepancias entre las cadenas, ya que, salvo en dos de las piezas emitidas por La sexta, todas ellas diferencian al $100 \%$ entre ambos contenidos. Por el contrario, en radio esto cambia radicalmente: mientras que la SER no incorpora opinión en el 100\% de sus noticias, Onda cero sí lo hace en el $87,5 \%$ de las veces y la COPE en el $40 \%$. En RNE la cifra baja visiblemente, ya que sólo un $16,7 \%$ de las piezas mezclan información y opinión.

En cuanto a "actualidad-inmediatez", el "hoy" impera en la mayoría de las noticias de Telecinco (72,7\%). A esta cadena le siguen La sexta (44\%), Antena 3 (40\%) y La primera (33,3\%). Este último operador no hace referencia alguna al "cuándo" en el $50 \%$ de sus piezas. El resto tiene un comportamiento más similar, ya que Antena 3 no lo hace en el 26,7\% de los casos, La sexta en el $20 \%$ y Telecinco en el $27,3 \%$. En radio, el medio tradicionalmente más inmediato, el "hoy" es mayoritario, aunque en el $62,5 \%$ de las entregas de la COPE no hay mención alguna al "cuándo". En RNE la ausencia de mención se sitúa en el $41,6 \%$, en la SER en el $27,3 \%$ y en Onda cero en el $20 \%$.

Por último, la diversidad de géneros periodísticos es muy escasa en todas las televisiones, ya que predomina la noticia (84\%). El otro género que se explota es el reportaje (o más bien la información reportajeada) con una presencia relativamente elevada en Antena 3 (33,3\% -5 piezas) y en La primera (22,2\% -4 piezas). En Telecinco (9,1\%) y en La sexta (4\%) su aparición es muy poco significativa, puesto que en ambos casos la información reportajeada solo aparece en una ocasión. Por su parte, la SER, en el 100\% de los casos, y RNE, en el 91,6\%, apuestan netamente por las noticias, mientras que Onda cero y la COPE diversifican algo más su oferta. Entre las unidades de análisis de Onda cero se encuentran una pieza de opinión y un editorial, mientras que en las de la COPE sorprende que no aparezca ninguna noticia estricta y que, en cambio, se contabilicen tres entrevistas, dos editoriales y otros formatos.

Para visualizar la posición en la que se sitúa cada medio en relación con los indicadores que explican las cuatro variables estudiadas, al final de cada apartado se ha elaborado un índice que evalúa, en una escala de 1 a 4, el comportamiento observado, siendo 1 el mejor valor y 4 el peor. Así, por ejemplo, a la cadena de televisión o la emisora de radio que utiliza más fuentes propias, según se desprende del análisis de contenido, se le asigna un punto, mientras que la que usa el número menor recibe 4 puntos. Lo mismo se hace con el resto de los criterios. Por otra parte, en el caso de que el comportamiento de dos o más operadores sea idéntico, se adjudica la misma puntuación. La tabla 3 muestra el índice de credibilidad alcanzado por los medios tras el análisis de contenido. 
Tabla 3. Índice de credibilidad de los medios tras el análisis de contenido

\begin{tabular}{|c|c|c|c|c|}
\hline Televisión & La primera (TVE) & Telecinco & Antena 3 & La sexta \\
\hline Número de fuentes & 3 & 4 & 1 & 2 \\
\hline Acceso a las fuentes & 4 & 2 & 3 & 1 \\
\hline Uso de fuentes propias & 2 & 1 & 3 & 3 \\
\hline Autoría de las piezas & 3 & 4 & 1 & 2 \\
\hline Autoría de las imágenes & 3 & 4 & 2 & 1 \\
\hline Distinción información /opinión & 1 & 1 & 1 & 2 \\
\hline Actualidad-inmediatez & 4 & 1 & 3 & 2 \\
\hline Diversidad de géneros & 2 & 3 & 1 & 4 \\
\hline Total puntos* & 22 & 20 & 15 & 17 \\
\hline Radio & COPE & Onda cero & RNE & SER \\
\hline Número de fuentes & 4 & 3 & 1 & 2 \\
\hline Acceso a las fuentes & 1 & 1 & 2 & 3 \\
\hline Uso de fuentes propias & 3 & 3 & 2 & 1 \\
\hline Autoría de las piezas & 1 & 1 & 1 & 1 \\
\hline Distinción información/opinión & 3 & 4 & 2 & 1 \\
\hline Actualidad-inmediatez & 4 & 1 & 3 & 2 \\
\hline Diversidad de géneros & 1 & 2 & 3 & 4 \\
\hline Total puntos* & 17 & 15 & 14 & 14 \\
\hline
\end{tabular}

*En función de la escala utilizada, a menor número de puntos, mejor posición.

Estos datos revelan una marcada correlación con los arrojados por las encuestas a los profesionales y a la población informada en su valoración de la credibilidad, sobre todo en radio y, especialmente, en la coincidencia de relegar a la COPE a la última posición (gráfico 1). Por lo que se refiere a los primeros puestos, la percepción que de la SER tienen los profesionales, que la conciben como la más creíble, coincide con el resultado obtenido por esta emisora en el análisis de contenido, donde se sitúa en primera posición junto a RNE. En televisión, la discrepancia más notable se observa con La primera (TVE), un canal que, si para los profesionales es el más creíble, en el análisis de contenido logra los peores resultados. En cambio, sí coinciden las valoraciones de la población informada, que también colocan a Antena 3 y a $L a$ sexta a la cabeza del ranking.

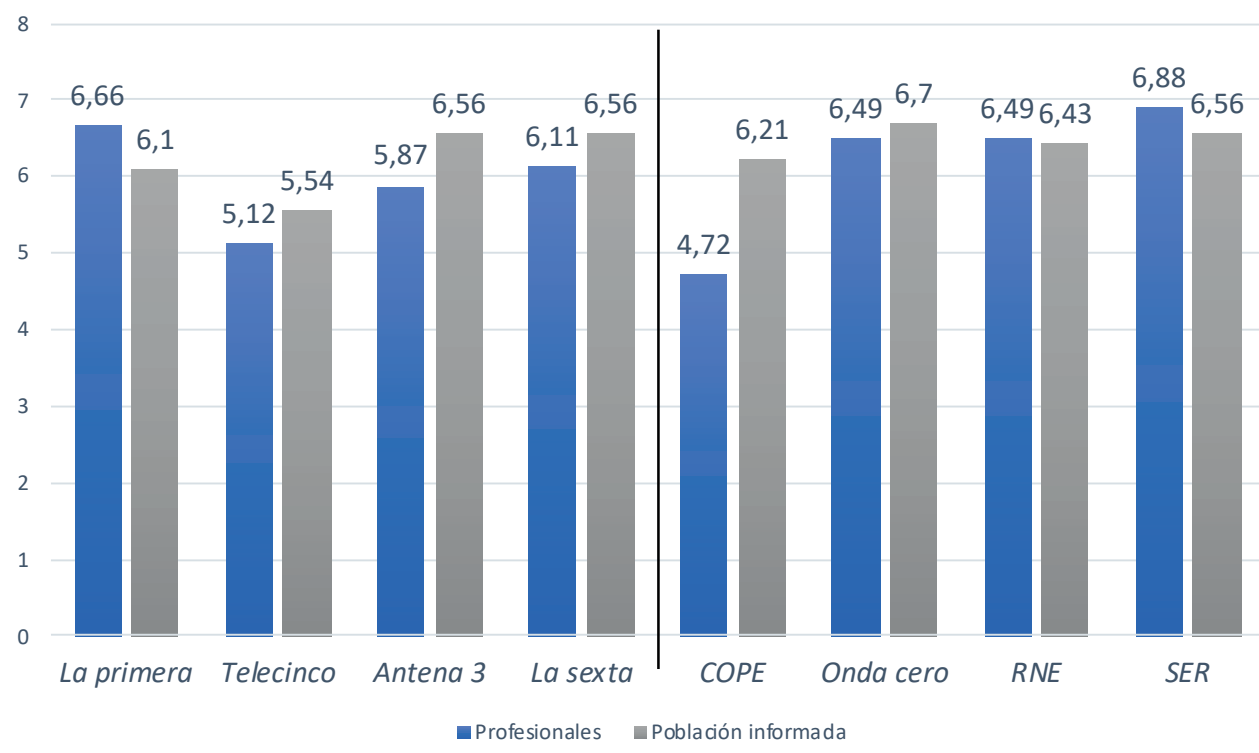

Gráfico 1. Credibilidad de los medios según los profesionales y la población informada (los datos expresan la puntuación media sobre 10)

\subsection{Rigor informativo}

El análisis de contenido sobre los indicadores para evaluar esta dimensión sitúa a La primera (TVE) y a La sexta en los primeros puestos televisivos, mientras que en radio la COPE, al igual que sucedía con la credibilidad, ocupa el último lugar (tabla 5). Los datos revelan que en las cadenas mejor posicionadas inciden en términos muy similares la mención 
del origen de las informaciones que difunden, la estructura de la información y los profesionales que intervienen en la elaboración de las piezas. En radio, la emisora más rigurosa según el análisis de contenido -Onda cero- es la que más alude al origen de la información y la que incluye en sus noticias más citas de actores no periodísticos.

El estudio de los parámetros que influyen sobre el rigor informativo evidencia que el origen de la información se menciona en la práctica totalidad de las piezas televisivas. De hecho, la cuota alcanza el $100 \%$ en todas las cadenas, salvo en La primera (TVE), un canal en el que no se menciona el origen en dos de sus informaciones. En radio, a este indicador se alude igualmente en la práctica totalidad de las entregas, especialmente en Onda cero, donde alcanza el 100\%; RNE, con el 91,7\%; y la $S E R$, con el 90,9\%, le siguen muy de cerca en el ranking. En COPE, la inexistencia de noticias propiamente dichas implica que en ningún caso haya referencias a este aspecto.

Por lo que respecta a la estructura narrativa de las piezas, el formato clásico de entradilla+VTR (video) es el predominante (45\%) en la oferta informativa de televisión, junto con otras combinaciones entre las que destacan el VTR con voz en off o la fórmula entradilla+VTR+ conexión en directo. La primera (TVE) tiene la mayor variedad en cuanto a formatos -aunque con un predominio de la entradilla+VTR (33,3\%)- seguida por La sexta, Telecinco y Antena 3. Además de en La primera (TVE), la entradilla+VTR también prevalece, en proporciones mucho más amplias, en Antena 3 (60\%) y en La sexta (56\%). En Telecinco aparece, en el 36,4\% de las ocasiones, la fórmula entradilla+cola+directo+declaraciones o totales, mientras que la entradilla+VTR lo hace en el $18,2 \%$ de las ocasiones.

En los medios audiovisuales es interesante estudiar también, en relación con la presentación de los contenidos, los profesionales que intervienen en cada pieza, en tanto que este indicador amplía la aproximación a la estructura informativa imperante en cada caso. La tabla 4 refleja cómo La primera (TVE) cuenta con una mayor diversidad de profesionales que el resto, aunque La sexta le sigue muy de cerca. Por el contrario, Telecinco apuesta significativamente por piezas en las que únicamente interviene el/la conductor/a del telediario.

Tabla 4. Televisión: profesionales que intervienen en cada pieza por cadenas (entre paréntesis, datos en \% sobre el total de cada cadena)

\begin{tabular}{|l|c|c|c|}
\hline \multicolumn{1}{|c|}{ Profesionales } & La primera (TVE) & Telecinco & Antena 3 \\
\hline Conductor & $7(38,9)$ & $5(45,5)$ & $2(13,3)$ \\
\hline Conductor + redactor & $6(33,3)$ & $1(9,1)$ & $10(66,7)$ \\
\hline Conductor + redactor + reportero & $3(16,7)$ & $1(9,1)$ & 0 \\
\hline Otros* & $2(11,1)$ & $4(36,4)$ & $2(8,0)$ \\
\hline Total cadena & 18 & 11 & $1(20,0)$ \\
\hline
\end{tabular}

*Incluyen, además de conductor, a analistas, responsables de contenidos, etc.

En la comunicación radiofónica cabe valorar positivamente aquellas informaciones, especialmente cuando se trata de noticias, que siguen la estructura entradilla-cuerpo-cierre, en tanto que dicha estructura, gracias a la redundancia del cierre, facilita la decodificación del mensaje. El análisis de contenido muestra que la emisora que más apuesta por este modelo narrativo es la SER, que lo sigue en el $90 \%$ de los casos. Tras ella se sitúa Onda cero, que lo aplica en el 37,5\% de las ocasiones y $R N E$, en el $10 \%$. En la COPE no se aprecia ninguna pieza que siga esta estructura. Por otro lado, el tándem conductor/redactor, que favorece una transmisión más ágil de las noticias radiofónicas, domina en la Cadena SER (100\% de las piezas). Esta práctica también tiene una elevada presencia en Onda cero (70\%), mientras que en el $30 \%$ restante solo interviene el conductor del programa. En RNE, el relato a dos voces aparece en el $41 \%$ de los casos. La COPE sustituye, al menos en el tratamiento del proceso de investidura, la figura del redactor por la del analista/experto.

La presencia de actores no periodísticos a los que se les da voz, es decir, sobre los que se incluye alguna cita o inserto, son mayoritariamente políticos en televisión $(69,6 \%)$, un dato lógico si se atiende a la temática seleccionada (campaña electoral). Telecinco incorpora personajes no periodísticos en 10 de sus piezas (90,9\%), La sexta en 21 (84\%), La primera (TVE) en $11(61,1 \%)$ y Antena 3 en 8 (53,3\%). En radio, donde abundan igualmente los políticos (57,5\%), Onda cero ofrece el mayor número de piezas con actores, 8 (80\%), seguida por $R N E$, con 6 (50\%). La COPE los introduce en 3 de las unidades de análisis (42,9\%) y la SER en 4 (36,4\%).

Por lo que se refiere a la localización, no se menciona lugar alguno (ciudad, comunidad autónoma, etc.) en el $80 \%$ de las 15 informaciones difundidas por Antena 3, una cifra muy superior a la del resto, pero muy especialmente con respecto a Telecinco, donde no se localizan 3 piezas (27,3\%). En La primera (TVE) no hay alusión a ningún lugar en el 61,1\% de los casos -11 de sus entregas- mientras que en La sexta esto sucede en el 56\% de las ocasiones, es decir, en 14 de sus noticias. En radio, la información no se sitúa territorialmente en un alto porcentaje de las piezas, puesto que no se alude a ningún lugar en 10 de las unidades de Onda cero (100\%), en 11 de las de $R N E(91,7 \%)$, y en seis de las de la COPE $(85,7 \%)$. En este aspecto, la emisora mejor posicionada es la SER, ya que no menciona lugar alguno en "solo" 7 de sus 11 entregas, es decir, en el 63,6\%.

Para establecer el índice de rigor informativo (tabla 5) se siguen los criterios explicados con anterioridad y se añaden los resultados obtenidos en los indicadores transversales "número de fuentes" y "diversidad de géneros periodísticos", que ya fueron analizados en el apartado sobre credibilidad. 
Tabla 5. Índice de rigor informativo de los medios tras el análisis de contenido

\begin{tabular}{|c|c|c|c|c|}
\hline Televisión & La primera (TVE) & Telecinco & Antena 3 & La sexta \\
\hline Origen de la información & 2 & 1 & 1 & 1 \\
\hline Estructura de la información & 1 & 3 & 4 & 2 \\
\hline Profesionales que intervienen & 1 & 4 & 3 & 2 \\
\hline Presencia de actores no periodísticos & 3 & 1 & 4 & 2 \\
\hline Localización de la información & 3 & 1 & 4 & 2 \\
\hline Número de fuentes & 3 & 4 & 1 & 2 \\
\hline Diversidad de géneros & 2 & 3 & 1 & 4 \\
\hline Total puntos* & 15 & 17 & 18 & 15 \\
\hline Radio & COPE & Onda cero & RNE & SER \\
\hline Origen de la información & 4 & 1 & 2 & 3 \\
\hline Estructura de la información & 4 & 2 & 3 & 1 \\
\hline Profesionales que intervienen & 4 & 2 & 3 & 1 \\
\hline Presencia de actores no periodísticos & 3 & 1 & 2 & 4 \\
\hline Localización de la información & 2 & 4 & 3 & 1 \\
\hline Número de fuentes & 4 & 3 & 1 & 2 \\
\hline Diversidad de géneros & 1 & 2 & 3 & 4 \\
\hline Total puntos* & 22 & 15 & 17 & 16 \\
\hline
\end{tabular}

*En función de la escala utilizada, a menor número de puntos, mejor posición.

En la valoración del rigor informativo, los profesionales sitúan a La primera (TVE) en la mejor posición, con 6,56 puntos sobre 10, mientras que Telecinco ocupa el último lugar, con 5,12 (gráfico 2). Por su parte, la población informada otorga la mayor puntuación a Antena $3(6,29)$, aunque seguida muy de cerca por La sexta $(6,28)$. En radio, a diferencia de lo que sucede en televisión, existe mayor armonía entre los resultados del análisis de contenido y las valoraciones de los encuestados, especialmente en el caso de la población informada, con la que las coincidencias son plenas. Para los profesionales, la SER, que en el análisis de contenido se sitúa en segundo lugar, aunque muy cerca de Onda cero, es, con 6,82 puntos, la mejor posicionada en esta variable.

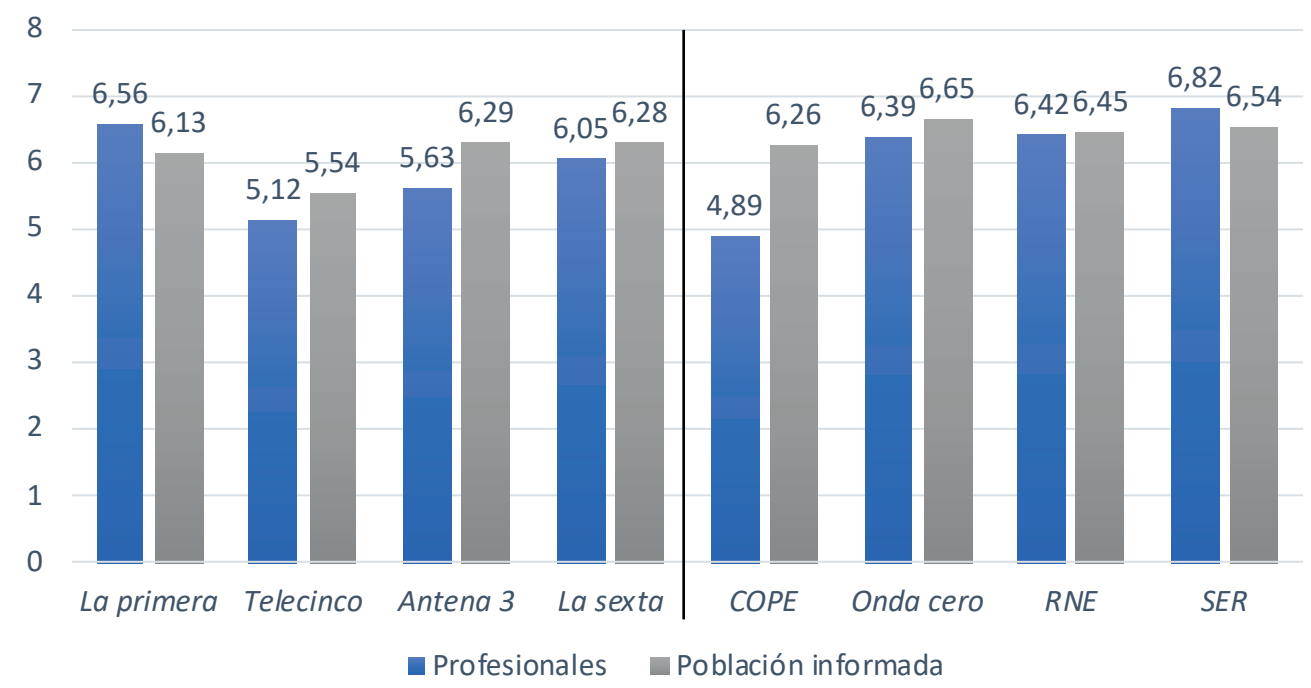

Gráfico 2. Rigor informativo de los medios según los profesionales y la población informada (los datos expresan la puntuación media sobre 10)

\subsection{Calidad periodística}

Los resultados del análisis de contenido sobre la calidad periodística colocan a La sexta y a RNE en las primeras posiciones, mientras que Telecinco y la COPE ocupan los últimos lugares (tabla 8). Los datos sugieren que, en el caso de la cadena de televisión mejor situada, inciden la cantidad de información que ofrece, la mención al origen de la misma y la diversificación en cuanto a criterios de noticiabilidad. En radio, la incidencia mayor viene dada igualmente por la cantidad de entregas y los criterios de noticiabilidad, aunque a idéntico nivel se sitúan el número de fuentes, la atribución de autoría y el enfoque de las piezas. 
Si para medir la cantidad de información se toma como referente el número de piezas que incluye cada medio, se observa una clara ventaja de La sexta, especialmente si se compara con Telecinco. Con 25 entregas, La sexta acumula el $36,2 \%$ de las 69 unidades de análisis que durante los días observados emitieron las cuatro cadenas. Al canal del grupo Atresmedia le siguen La primera (TVE), con 18 piezas (26,1\%), Antena 3, con 15 (21,7\%) y Telecinco, con 11 (15,9\%). En radio, apenas existen diferencias entre la mayoría de las emisoras, pero sí entre la COPE y el resto. Como ya mostraba la tabla 1, la cadena que más información ofreció sobre el proceso de investidura en los días estudiados fue $R N E$, con 12 (30\% del total), seguida por la SER, con $11(27,5 \%)$, Onda cero, con $10(25 \%)$ y la COPE, con $7(17,5 \%)$.

Por lo que se refiere al enfoque de las piezas dedicadas a la campaña electoral de noviembre de 2019, el mayor índice de neutralidad en televisión se aprecia en La primera (TVE), en tanto que así se presentan el 33,3\% de sus informaciones (tabla 6). Las cadenas menos neutrales son Telecinco, donde sobresale el enfoque negativo (63,6\%) y Antena 3 (60\%).

Tabla 6. Televisión: enfoque de las piezas por cadenas (entre paréntesis, datos en porcentaje sobre el total de cada cadena)

\begin{tabular}{|l|c|c|c|}
\hline \multicolumn{1}{|c|}{ Enfoque } & La primera (TVE) & Telecinco & Antena 3 \\
\hline Positivo & $7(38,9)$ & $4(36,4)$ & $2(13,3)$ \\
\hline Negativo & $5(27,8)$ & $7(63,6)$ & $9(60,0)$ \\
\hline Neutro & $6(33,3)$ & 0 & $4(26,7)$ \\
\hline Total cadena & 18 & 11 & $15(40,0)$ \\
\hline
\end{tabular}

En radio, la neutralidad en relación con el proceso de investidura de 2020 es mayor en $R N E$, en tanto que así se presentan el $91,7 \%$ de sus entregas (tabla 7). Este dato sorprende si se compara con las cuotas que alcanzan las otras emisoras: la SER es neutral en el $18,2 \%$ de sus piezas, mientras que la COPE lo es en el 14,3\% y Onda cero en tan solo el $10 \%$. También es llamativa la negatividad de la $\operatorname{COPE}(85,7 \%)$ frente a la positividad de la SER $(63,6 \%)$. Como ejemplo que ilustra esta negatividad, en el enfoque de sus informaciones sobre la investidura algunas de las palabras pronunciadas por el conductor de La linterna (COPE) en su edición del día 6 de enero de 2020 fueron estas:

"lo que hemos oído en el congreso estos días es un escupitajo a la Constitución" (...) "tiparraca de Bildu" (...) "el problema explosivo es cuando Sánchez no dice ni mú, es más, hasta les da las gracias" (...) "escupitajos apestosos que lanzaron con todo su odio y toda su mala baba" (...) “¿gobierno progresista? ¡Ja!" (...) "la bancada socialista se baja los pantalones".

Por el contrario, la positividad de la SER se percibe en enfoques como estos:

"la investidura estaría garantizada; la última pieza ha encajado" (...) "Bildu contribuirá a facilitar la investidura de Sánchez" (Hora 25, 3 de enero de 2020).

"Uno de los factores que puede combatir la debilidad parlamentaria con la que nace este gobierno es que la radicalidad de la oposición de derechas funcione prácticamente como casi un cemento, como argamasa del gobierno y sus aliados parlamentarios. PP, Vox y Ciudadanos han dejado claro que preparan una oposición de extrema dureza (Hora 25, 6 de enero de 2020).

"El UBS -en referencia a la sociedad suiza de servicios financieros- dice que no prevé grandes cambios con el nuevo gobierno, frente a los augurios apocalípticos" (Hora 25, 7 de enero de 2020).

Tabla 7. Radio: enfoque de las piezas por emisoras (entre paréntesis, datos en \% sobre el total de cada emisora)

\begin{tabular}{|c|c|c|c|c|}
\hline Enfoque & COPE & Onda cero & RNE & SER \\
\hline Positivo & 0 & $2(20,0)$ & $1(8,3)$ & $7(63,6)$ \\
\hline Negativo & $6(85,7)$ & $7(70,0)$ & 0 & $2(18,2)$ \\
\hline Neutro & $1(14,3)$ & $1(10,0)$ & $11(91,7)$ & $2(18,2)$ \\
\hline Total emisora & 7 & 10 & 12 & 11 \\
\hline
\end{tabular}

En criterios de noticiabilidad, la actualidad prima en todas las cadenas de televisión, hasta el punto de que es el principal criterio en el $100 \%$ de las ocasiones. No obstante, si se profundiza en este indicador, se percibe cómo, cuando a la actualidad se suman otros (relevancia personal de los actores que aparecen en las piezas, proximidad, conflicto o consecuencias), La sexta es la que presenta una mayor diversificación, seguida por Antena 3, La primera y Telecinco. En radio, la actualidad es también el criterio imperante, especialmente en la COPE, aunque si se ahonda en esta cuestión se observa que RNE es la que opta por una variedad más destacada, seguida por la SER, Onda cero y, en último lugar, la COPE.

Para establecer el índice sobre la calidad periodística (tabla 8) se siguen los pasos explicados anteriormente y se añaden los resultados obtenidos en los indicadores "número de fuentes"; "autoría de las piezas"; "actualidad-inmediatez"; "diversidad de géneros"; "origen de la información"; "estructura de la información"; "profesionales que intervienen" y "presencia de actores no periodísticos", que ya fueron tratados en los apartados precedentes. 
Tabla 8. Índice de calidad periodística de los medios tras el análisis de contenido

\begin{tabular}{|c|c|c|c|c|}
\hline Televisión & La primera (TVE) & Telecinco & Antena 3 & La sexta \\
\hline Cantidad de información & 2 & 4 & 3 & 1 \\
\hline Enfoque de las piezas & 1 & 4 & 3 & 2 \\
\hline Criterios de noticiabilidad & 3 & 4 & 2 & 1 \\
\hline Número de fuentes & 3 & 4 & 1 & 2 \\
\hline Autoría de las piezas & 3 & 4 & 1 & 2 \\
\hline Actualidad-inmediatez & 4 & 1 & 3 & 2 \\
\hline Diversidad de géneros & 2 & 3 & 1 & 4 \\
\hline Origen de la información & 2 & 1 & 1 & 1 \\
\hline Estructura de la información & 1 & 3 & 4 & 2 \\
\hline Profesionales que intervienen & 1 & 4 & 3 & 2 \\
\hline Presencia de actores no periodísticos & 3 & 1 & 4 & 2 \\
\hline Total puntos* & 25 & 33 & 26 & 21 \\
\hline Radio & COPE & Onda cero & RNE & SER \\
\hline Cantidad de información & 4 & 3 & 1 & 2 \\
\hline Enfoque de las piezas & 3 & 4 & 1 & 2 \\
\hline Criterios de noticiabilidad & 4 & 3 & 1 & 2 \\
\hline Número de fuentes & 4 & 3 & 1 & 2 \\
\hline Autoría de las piezas & 1 & 1 & 1 & 1 \\
\hline Actualidad-inmediatez & 4 & 1 & 3 & 2 \\
\hline Diversidad de géneros & 1 & 2 & 3 & 4 \\
\hline Origen de la información & 4 & 1 & 2 & 3 \\
\hline Estructura de la información & 4 & 2 & 3 & 1 \\
\hline Profesionales que intervienen & 4 & 2 & 3 & 1 \\
\hline Presencia de actores no periodísticos & 3 & 1 & 2 & 4 \\
\hline Total puntos* & 36 & 23 & 21 & 24 \\
\hline
\end{tabular}

*En función de la escala utilizada, a menor número de puntos, mejor posición.

En las encuestas a los profesionales y a la población informada, la calidad periodística fue una variable que se sometió únicamente a la consideración de los primeros, por lo que la comparación se limita a los resultados obtenidos en este caso. En televisión, los profesionales consideran que la calidad periodística es mayor en La primera (TVE), que en esta dimensión consigue 6,62 puntos, aunque La sexta, situada en primer lugar tras el análisis de contenido, le sigue muy de cerca, con 6,25. La peor valorada es Telecinco, que logra 5,36 puntos, mientras que Antena 3 recibe 5,83 (gráfico 3). En radio, el análisis de contenido coincide con el segundo puesto que ostenta Onda cero a juicio de los profesionales y con

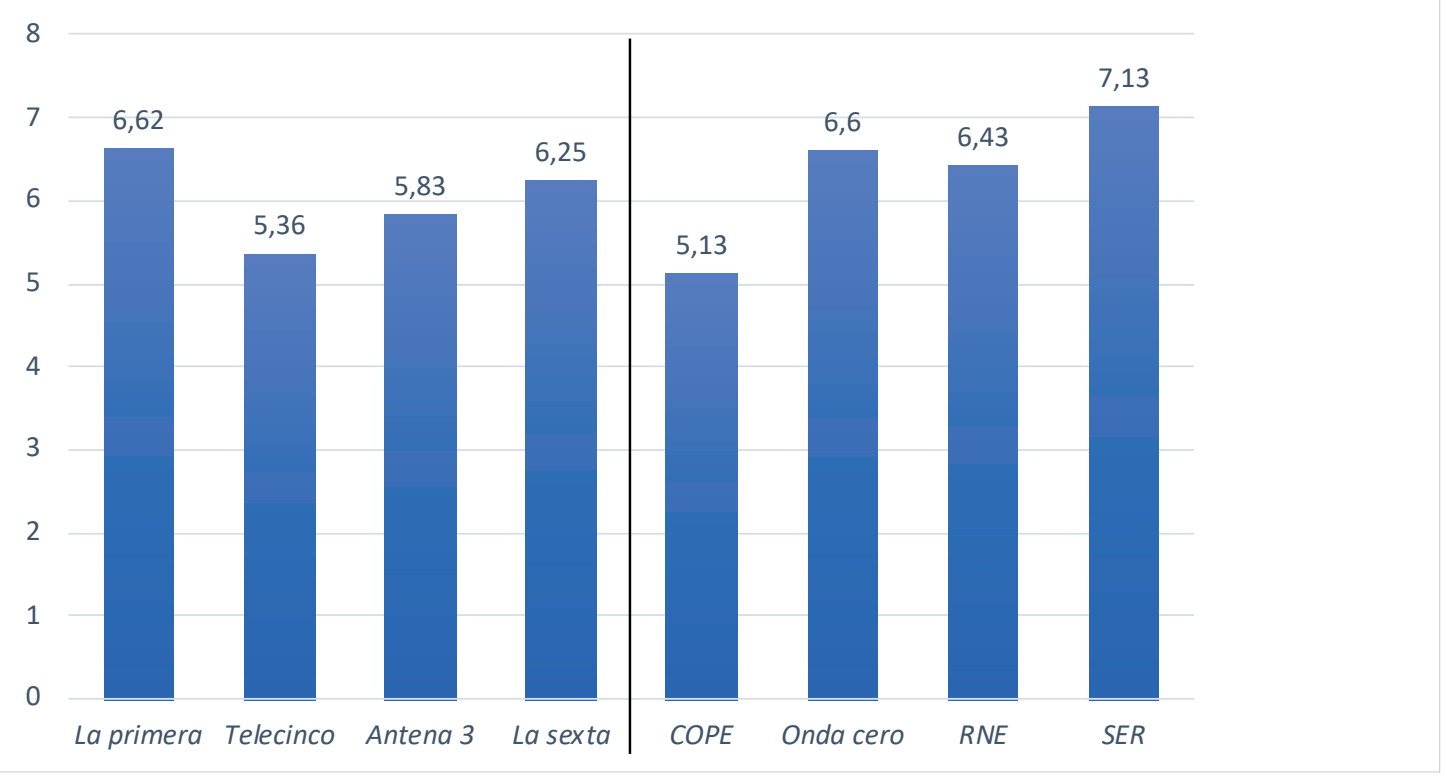

Gráfico 3. Calidad periodística de los medios según los profesionales (los datos expresan la puntuación media sobre 10) 
la última posición de la COPE, pero en cambio presenta diferencias significativas en relación con la calidad informativa que la muestra atribuye a la $S E R$, que con 7,13 puntos supera a $R N E(6,43)$.

\section{4. Ética y deontología profesional}

La disposición a rectificar en caso de error, la paridad en el uso de actores no periodísticos y la no presencia de opinión en las piezas informativas son los tres indicadores que se establecieron para evaluar esta dimensión, puesto que el análisis de contenido no permite medir objetivamente otros parámetros. Sin embargo, ninguna de las 109 unidades de análisis ha incorporado rectificación alguna sobre informaciones anteriormente difundidas por las cadenas de televisión o las emisoras de radio, por lo que se ha decidido desestimar este criterio. Por lo que se refiere a la paridad informativa, la investigación se ha acotado a los actores no periodísticos que, en las piezas que los contienen, aparecen en las tres primeras posiciones (actor 1, actor 2 y actor 3). En total se han contabilizado 120 actores $^{4}$ en el caso de la televisión (91 hombres -75,8\%- y 29 mujeres -24,2\%-) y 30 en el de la radio (20 hombres -66,7\%- y 10 mujeres -33,3\%-).

Entre los actores que en las piezas televisivas aparecen en primera posición ( $n=51)$, los 38 hombres (74,5\%) dominan frente a las 13 mujeres (25,5\%). La cadena con un mayor índice de paridad es La primera (TVE), seguida por Telecinco, La sexta y Antena 3 (tabla 9).

Tabla 9. Televisión: distribución del actor 1 por cadenas y sexo $(n=51)$. Entre paréntesis, datos en $\%$ sobre el total de actores 1 en cada cadena.

\begin{tabular}{|l|c|c|c|}
\hline \multicolumn{1}{|c|}{ Sexo } & La primera (TVE) & Telecinco & Antena 3 \\
\hline Hombre & $7(63,6)$ & $7(70,0)$ & $8(88,9)$ \\
\hline Mujer & $4(36,4)$ & $3(30,0)$ & $1(11,1)$ \\
\hline Total actor 1 & 11 & 10 & $9(76,2)$ \\
\hline
\end{tabular}

En cuanto a los actores que aparecen en segundo lugar $(n=38)$, La sexta es la más paritaria $(73,7 \%$ de hombres frente a $26,3 \%$ de mujeres) aunque seguida muy de cerca por La primera (77,8\% frente a 22,2\%). La menos paritaria es Telecinco, ya que el $100 \%$ de los personajes en segunda posición son hombres, mientras que en Antena 3 los hombres son el $87,5 \%$ y las mujeres el $12,5 \%$. Finalmente, la paridad más alta en cuanto al actor $3(n=31)$, se da de nuevo en La primera $(66,7 \%$ de hombres frente a $33,3 \%$ de mujeres). A esta cadena le siguen Antena 3 (71,4\% por 28,6\%), La sexta (75\% por $25 \%)$ y Telecinco, donde los actores vuelven a ser hombres.

En radio, entre los actores que aparecen en primera posición $(n=20)$, aun cuando los hombres $(60 \%)$ dominan frente a las mujeres (40\%), la distancia entre ambos sexos es significativamente más corta que en televisión. La emisora con mayor índice de paridad es $R N E$, mientras que Onda cero es la menos paritaria (tabla 10). La SER y la COPE empatan en este indicador, aunque con resultados inversos: si en la primera predominan las mujeres $(66,7 \%)$ en la segunda son los hombres los que logran ese porcentaje. En cuanto a los actores en posición 2 y 3, la limitación numérica (10) y su dispersión entre las radios desaconsejan tenerlos en cuenta dada su escasa incidencia.

Tabla 10. Radio: distribución del actor 1 por emisoras y sexo $(n=20)$. Entre paréntesis, datos en \% sobre el total de actores 1 en cada emisora.

\begin{tabular}{|l|c|c|c|c|}
\hline \multicolumn{1}{|c|}{ Sexo } & COPE & Onda cero & RNE & SER \\
\hline Hombre & $2(66,7)$ & $6(75,0)$ & $3(50,0)$ & $1(33,3)$ \\
\hline Mujer & $1(33,3)$ & $2(25,0)$ & $3(50,0)$ & $2(66,7)$ \\
\hline Total actor 1 & 3 & 8 & 6 & 3 \\
\hline
\end{tabular}

En función de los indicadores explotados, el índice sobre ética y deontología profesional, que incorpora también los resultados obtenidos en cuanto a distinción entre información y opinión, se comporta como muestra la tabla 11.

Tabla 11. Índice sobre ética y deontología profesional tras el análisis de contenido

\begin{tabular}{|c|c|c|c|c|}
\hline Televisión & La primera (TVE) & Telecinco & Antena 3 & La sexta \\
\hline Paridad actor 1 & 1 & 2 & 4 & 3 \\
\hline Paridad actor 2 & 2 & 4 & 3 & 1 \\
\hline Paridad actor 3 & 1 & 4 & 2 & 3 \\
\hline Distinción información/opinión & 1 & 1 & 1 & 2 \\
\hline Total puntos* & 5 & 11 & 10 & 9 \\
\hline Radio & COPE & Onda cero & RNE & SER \\
\hline Paridad actor 1 & 2 & 3 & 1 & 2 \\
\hline Distinción información/opinión & 3 & 4 & 2 & 1 \\
\hline Total puntos* & 5 & 7 & 3 & 3 \\
\hline
\end{tabular}

*En función de la escala utilizada, a menor número de puntos, mejor posición. 


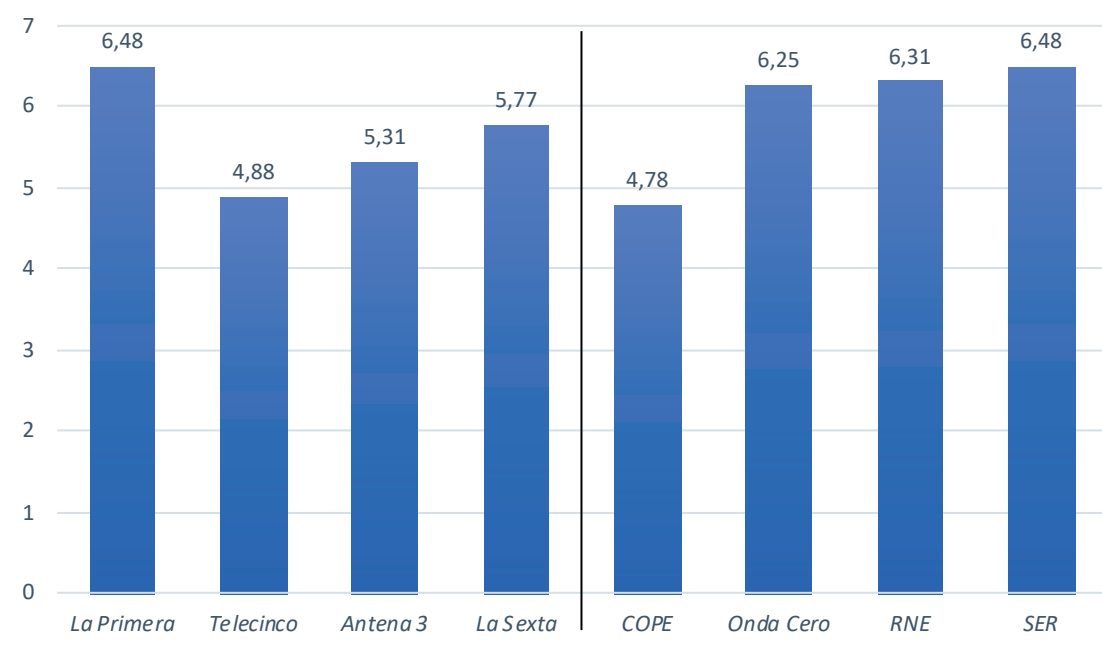

Gráfico 4. Ética y deontología en los medios según los profesionales (los datos expresan la puntuación media sobre 10)

Al igual que sucedía con la calidad periodística, en las encuestas a los profesionales y a la población informada, la ética y deontología profesional se sometió solo a la consideración de los primeros, por lo que la comparación se limita a los resultados obtenidos en este caso. En televisión, los profesionales otorgan a La primera (TVE) la mejor puntuación (gráfico 4) y a Telecinco la peor, lo mismo que refleja el análisis de contenido, que también sitúa a La sexta en segundo lugar y a Antena 3 en tercero. En radio, la cadena SER es la mejor valorada por los profesionales, seguida de RNE, las dos emisoras que tras el análisis de contenido se colocan a la cabeza del ranking. En general, los profesionales consideran que la ética y la deontología profesional es una característica más intrínseca al medio radiofónico. Esta circunstancia sintoniza con los resultados del análisis, los cuales evidencian, como se ha visto, que la radio es más paritaria que la televisión a la hora de dar voz a los actores no periodísticos.

\subsection{Reputación}

Los resultados de las encuestas a los profesionales y a la población informada que se han manejado en esta investigación se utilizaron, como ya se avanzaba en el apartado 2, para establecer un ranking de valoración de la reputación de los medios por parte de ambas muestras. Para la elaboración de dicho ranking se consideraron seis variables profesionales -credibilidad, rigor informativo, calidad periodística, ética y deontología profesional, independencia y contribución a la democracia- y cuatro empresariales -sostenibilidad económica, transparencia en la gestión empresarial, responsabilidad de la propiedad y derechos y deberes de los trabajadores-. Si se hace lo mismo con los datos obtenidos en el análisis de contenido y se propone un ranking general de valoración de la reputación mediática a partir de las cuatro dimensiones estudiadas, las cadenas de televisión muestran unas distancias más marcadas que las emisoras de radio, donde solo la COPE parece alejarse nítidamente de sus competidoras. Como muestra la tabla 12, que suma las puntuaciones obtenidas por cada medio tras el análisis de contenido, La sexta alcanza la primera posición en el ranking reputacional, seguida por La primera (TVE), Antena 3 y Telecinco. En radio, RNE se sitúa a la cabeza y tras ella se posicionan, por este orden, la SER, Onda cero y la COPE que, con 80 puntos, se distancia considerablemente del resto de emisoras.

Tabla 12. Valoración de la reputación general de los medios tras el análisis de contenido

\begin{tabular}{|c|c|c|c|c|}
\hline Televisión & La primera (TVE) & Telecinco & Antena 3 & La sexta \\
\hline Credibilidad & 22 & 20 & 15 & 17 \\
\hline Rigor informativo & 15 & 17 & 18 & 15 \\
\hline Calidad periodística & 25 & 33 & 26 & 21 \\
\hline Ética y deontología profesional & 5 & 11 & 10 & 9 \\
\hline Total* & 67 & 81 & 69 & 62 \\
\hline Radio & COPE & Onda cero & RNE & SER \\
\hline Credibilidad & 17 & 15 & 14 & 14 \\
\hline Rigor informativo & 22 & 15 & 17 & 16 \\
\hline Calidad periodística & 36 & 23 & 21 & 24 \\
\hline Ética y deontología profesional & 5 & 7 & 3 & 3 \\
\hline Total* & 80 & 60 & 55 & 57 \\
\hline
\end{tabular}

*En función de la escala utilizada, a menor número de puntos, mejor posición. 


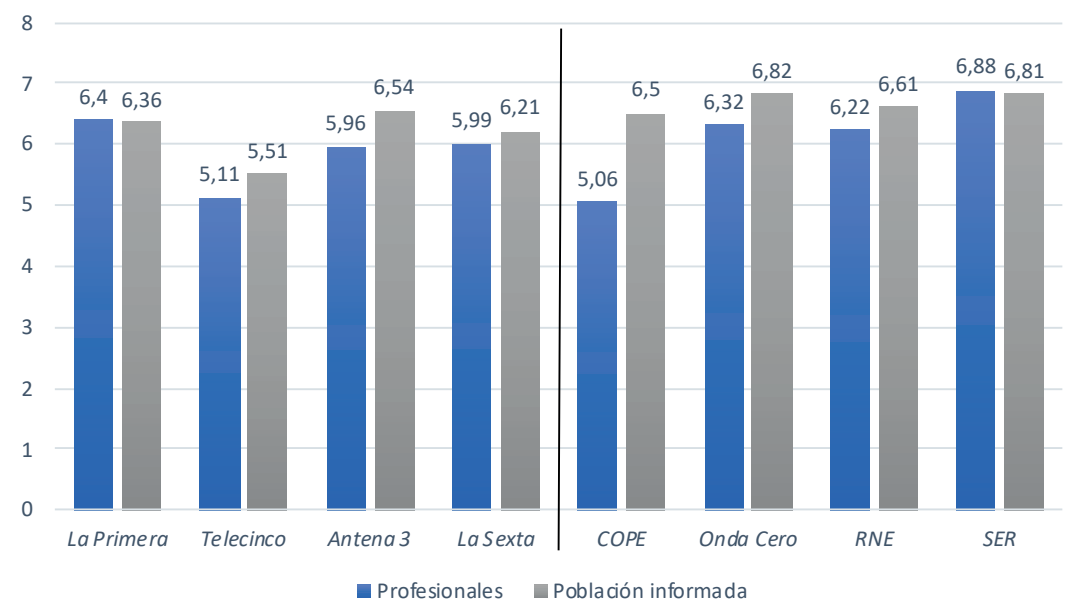

Gráfico 5. Valoración de la reputación general de los medios por los profesionales y la población informada (los datos expresan la puntuación media sobre 10)

Si los datos de la tabla 12 se comparan con la valoración de la reputación atribuida a cada medio por parte de los profesionales y de la población informada (gráfico 5), se ven alineaciones importantes, aunque somos conscientes de las disfunciones derivadas de considerar otras variables que en esta investigación, por las razones explicadas en su momento, se han descartado. En cualquier caso, en televisión la coincidencia es unánime a la hora de situar a Telecinco en última posición. Sin embargo, en relación con el resto de las cadenas, los resultados del análisis de contenido se corresponden más con el grado de reputación otorgado por los profesionales, que ponen a Antena 3 en tercer lugar, con 5,96 puntos, a La sexta en segundo $(5,99)$ y a La primera $(T V E)$ en primero $(6,4)$. En radio, la unanimidad también es clara a la hora de relegar al último puesto a la COPE. La población informada sitúa a Onda cero a la cabeza, con 6,82 puntos, y a la SER segunda, con 6,81, mientras que para los profesionales la SER es primera, con 6,88 puntos y Onda cero segunda, con 6,32 . El dato más discordante es el de $R N E$, que si el análisis de contenido la coloca en primera posición, tanto los profesionales como la población informada la emplazan al tercer lugar, con 6,22 y 6,61 puntos respectivamente.

\section{Conclusiones}

Este estudio establece un grado de coincidencia, en algunos casos significativo, entre el comportamiento de las variables periodísticas que intervienen en la arquitectura de los productos informativos y las percepciones que de estos tienen los públicos de interés de los medios de comunicación analizados. Por tanto, el tratamiento que recibe la información influye en la construcción de la reputación, y la credibilidad, el rigor informativo, la calidad periodística y la ética y deontología profesional son aspectos que contribuyen a la edificación de un importante intangible en un entorno mediático altamente competitivo.

En respuesta a las preguntas de investigación que se formulaban en el apartado 2, los resultados muestran que, en los medios mejor situados tras el análisis de contenido, las únicas correspondencias destacadas se dan en los casos de $L a$ primera $(T V E)$ y la SER, segundas en el ranking para la población informada y segundas también tras dicho análisis. En consecuencia, no se puede concluir que exista una alineación en las primeras posiciones, pero sí en las últimas: profesionales, población informada y análisis de contenido coinciden en relegar a la cola del ranking a Telecinco y a la COPE. Por otra parte, se observa que las coincidencias entre la valoración de los productos informativos y la opinión que de ellos se tiene son más evidentes en el caso de los profesionales, sobre todo en televisión. Esta circunstancia obedece, probablemente, a que este sector conoce las rutinas productivas de los medios y dispone de más elementos para juzgar aquellos contenidos que, bajo su criterio, resultan más creíbles, más rigurosos, etc. En cuanto a los medios con una coherencia más marcada entre lo que hacen y lo que los públicos piensan que hacen, no hay diferencias destacables entre la radio y la televisión, pero sí se ve que la imagen que proyectan La primera (TVE) y la SER, las mejor valoradas por los profesionales y las segundas para la población informada, se corresponde con el análisis de contenido, donde ambas alcanzan la segunda posición. En los casos de Telecinco y la COPE, las peores valoradas por los encuestados, la coherencia entre lo que hacen y lo que los públicos piensan que hacen es máxima. Finalmente, se detecta que, en el tratamiento de los contenidos informativos, la radio pública obtiene mejores resultados que sus competidoras en calidad periodística y empata con la SER, en primera posición, en credibilidad. Por su parte, la televisión pública destaca en rigor informativo y en ética y deontología profesional, donde también RNE se alinea con la SER en primera posición.

\section{El tratamiento que reciben los conteni- dos informativos influye en la construc- ción de la reputación que tienen los me- dios y en la imagen que proyectan}


Si bien el objetivo de esta investigación no ha sido establecer diferencias entre los medios analizados en función de su titularidad, los resultados muestran que tanto la televisión como la radio pública gozan de mayor credibilidad entre los profesionales, que sitúan a La primera (TVE) a la cabeza del ranking en esta variable y a RNE en segunda posición tras la Cadena SER. No obstante, es en ética y deontología profesional donde el sector público destaca netamente sobre el privado, tanto en el análisis de contenido como en la opinión que sobre $R N E$, pero especialmente sobre La primera (TVE), tienen los profesionales. Los datos obtenidos revelan, por otra parte, que, en general, en el ámbito de lo público la televisión logra mejores índices de reputación que la radio, hasta el punto de que La primera lidera el ranking de los profesionales y logra la segunda posición tanto para la población informada como en el análisis de contenido.

En contrapartida a las correlaciones explicadas, el estudio de los datos expuestos en este artículo muestra igualmente, salvo en los casos de Telecinco y la COPE, la existencia de discrepancias entre las valoraciones de los profesionales, la población informada y el análisis de contenido. Este hecho invita a que los resultados deban interpretarse como marcadores de tendencia, aunque bien es verdad que, a diferencia de las encuestas -que en relación con la reputación de los medios no pueden más que recoger impresiones subjetivas- el análisis de contenido aporta una visión más objetiva y cuantificable del comportamiento de las variables y los indicadores abordados, por lo que los índices parciales expresados y el ranking final resultante se ajustarían más a la realidad.

Investigaciones posteriores deberían arrojar luz sobre una cuestión que no ha quedado resuelta: ¿cuál es la dimensión periodística que más contribuye a la construcción de la reputación mediática? Por otro lado, también sería necesario establecer criterios objetivables que permitieran evaluar, a partir del análisis de los contenidos informativos, otras variables asociadas con la actividad profesional de los periodistas, como la independencia o la contribución a la democracia de las piezas que elaboran.

Una vez finalizado el estudio, entendemos que, además de avanzar en el conocimiento de la reputación mediática en España, el método utilizado en esta investigación puede ser extrapolable a contribuciones futuras que se centren en la prensa, un medio al que tradicionalmente se le ha atribuido un alto grado de credibilidad y rigurosidad. Del mismo modo, y dado que las redes sociales constituyen canales alternativos de información, trabajos ulteriores deberían centrarse en medir la reputación de los medios de comunicación en estos espacios con el fin de garantizar su pervivencia en el entorno digital.

\section{Notas}

1. La encuesta se realizó entre octubre y noviembre de 2018 y mayo de 2019 . Se trabajó con un cuestionario semiestructurado que se administró mediante llamada telefónica asistida por ordenador a través del sistema Computer-assisted telephone interviewing (CATI). Para un nivel de confianza del 95,5\% y en las condiciones habituales de muestreo $(p=q=50 \%)$, el margen de error para el total de la muestra sin segmentar fue de $\pm 8,4 \%$.

2. Se efectuó una encuestación Computer-assisted web interviewing (CAWI) con panel, entre octubre y noviembre de 2018, a partir, igualmente, de un cuestionario semiestructurado. Para un nivel de confianza del 95,5\% y en las condiciones habituales de muestreo $(p=q=50 \%)$, el margen de error para el total de la muestra sin segmentar fue de $\pm 3,1 \%$.

3. El listado incluye los 16 aspectos comunes sobre los que el equipo investigador extrajo información, aunque no todos han sido explotados para la elaboración de este artículo.

4. El número de actores que aparecen en las tres posiciones no significa que se trate de personajes distintos. Cada actor, aún siendo el mismo, se ha computado siempre que se incluyeran declaraciones.

\section{Referencias}

Balsebre, Armand (1994). La credibilidad de la radio informativa. Barcelona: Feed-back ediciones. ISBN: 8487799043

Barbeito-Veloso, María-Luz; Perona-Páez, Juan-José (2019). “Comunicación organizacional en clave sonora: el caso de Blink, los podcasts de BBVA". El profesional de la información, v. 28, n. 5, e280511. https://doi.org/10.3145/epi.2019.sep.11

Berens, Guido; Van-Riel, Cees B. M. (2004). “Corporate associations in the academic literature: three main streams of thought in the reputation measurement literature". Corporate reputation review, v. 7, n. 2, pp. 161-178.

https://doi.org/10.1057/palgrave.crr.1540218

Cadena SER (2019). "La SER, víctima de un ciberataque". Cadena SER, 4 noviembre. https://cadenaser.com/ser/2019/11/04/sociedad/1572862102_968725.html

Calvo-Porral, Cristina; Martínez-Fernández, Valentín-Alejandro; Juanatey-Boga, Óscar (2014). “Credibilidad de los medios de comunicación: análisis de la prensa diaria desde el comportamiento del consumidor". El profesional de la información, v. 23, n. 3, pp. 300-309.

https://doi.org/10.3145/epi.2014.may.10 
Campos-Freire, Francisco; Soengas-Pérez, Xosé; Rodríguez-Castro, Marta (2018). Indicadores de evaluación de los servicios informativos de la radiotelevisión pública. El profesional de la información, v. 27, n. 2, pp. 267-277.

https://doi.org/10.3145/epi.2018.mar.05

Carrillo, Victoria; Castillo-Díaz, Ana; Tato-Jiménez, Juan-Luis (2008). "El valor de lo intangible. La gestión de la reputación corporativa. El caso de la marca Telefónica”. OBS* observatorio journal, v. 2, n. 4, pp. 239-254.

http://obs.obercom.pt/index.php/obs/article/view/123

Cornell, Bradford; Shapiro, Alan C. (1987). "Corporate stakeholders and corporate finance”. Financial management, v. 16, n. 1, pp. 4-14.

https://www.researchgate.net/publication/247687908_Corporate_Stakeholders_and_Corporate_Finance

De-la-Fuente-Sabaté, Juan-Manuel; De-Quevedo-Puente, Esther (2003). "The concept and measurement of corporate reputation: an application to Spanish financial intermediaries". Corporate reputation review, v. 5, n. 4, pp. $280-301$. https://doi.org/10.1057/palgrave.crr.1540180

Diezhandino-Nieto, María-Pilar; Montiel-Jiménez, Esther; Marinas-Herreras, José-Miguel (2007). Periodismo y poder: políticos, periodistas y ciudadanos voluntariamente desinformados. Madrid: Pearson Prentice Hall. ISBN: 848322366 X

Edelman Trust Barometer (2020).

https://www.edelman.com/sites/g/files/aatuss191/files/2020-01/2020\%20Edelman\%20Trust\%20Barometer\%20 Global\%20Report_LIVE.pdf

Gaziano, Cecilie; McGrath, Kristin (1986). “Measuring the concept of credibility”. Journalism quarterly, v. 63, pp. 451-462. https://doi.org/10.1177/107769908606300301

Hayes, Arthur S.; Singer, Jane B.; Ceppos, Jerry (2007). "Shifting roles, enduring values: The credible journalist in a digital age". Journal of mass media ethics, v. 22, n. 4, pp. 262-279.

https://doi.org/10.1080/08900520701583545

Hill, Charles W. L.; Jones, Thomas M. (1992). "Stakeholder-agency theory". Journal of management studies, v. 29, n. 2, pp. 131-154.

http://faratarjome.ir/u/media/shopping_files/store-EN-1485783393-748.pdf

Hultén, Bertil; Broweus, Niklas; Van-Dijk, Marcus (2009). Sensory marketing. Bristol (UK): Palgrave Macmillan. ISBN: 02 30576575

Jensen, Michael C.; Meckling, William H. (1976). "Theory of the firm: managerial behavior, agency costs and ownership structure". Journal of financial economics, v. 3, n. 4, pp. 305-360.

https://doi.org/10.1016/0304-405X(76)90026-X

Lange, Donald; Lee, Peggy M.; Dai, Ye (2011). “Organizational reputation: a review”. Journal of management, v. 37, n. 1, pp. 153-184.

https://doi.org/10.1177/0149206310390963

Lenderman, Max; Sánchez, Raúl (2008). Marketing experiencial. La revolución de las marcas. Madrid: Esic editorial. ISBN: 9788473565455

Manzano, Roberto; Gavilán, Diana; Avello, María; Abril, Carmen; Serra, Teresa (2012). Marketing sensorial: comunicar con los sentidos en el punto de venta. Madrid: Pearson. ISBN: 9788483228128

Metzger, Miriam J.; Flanagin, Andrew J.; Eyal, Keren; Lemus, Daisy R.; McCann, Robert M. (2003). “Credibility for the $21^{\text {st }}$ century: Integrating perspectives on source, message, and media credibility in the contemporary media environment". Annals of the International Communication Association, v. 27, pp. 293-335.

https://doi.org/10.1080/23808985.2003.11679029

Moral, María; Fernández-Alles, María-Teresa (2012). “Nuevas tendencias del marketing: el marketing experiencial”. Entelequia. Revista interdisciplinar, n. 14, pp. 237-251.

https://revistaentelequia.wordpress.com/2012/05/01/nuevas-tendencias-del-marketing-el-marketing-experiencial

Newhagen, John; Nass, Clifford (1989). “Differential criteria for evaluating credibility of newspapers and TV news". Journalism and mass communication quarterly, n. 66, pp. 277-284.

https://doi.org/10.1177/107769908906600202

Newman, Nic; Fletcher, Richard (2017). "Bias, bullshit and lies audience perspectives on low trust in the media”. Digital news project 2017. Reuters Institute for the Study of Journalism/University of Oxford.

https://doi.org/10.2139/ssrn.3173579 
Ortiz-de-Guinea, Yolanda (2015). "El periodismo y la reputación de los periodistas en tiempos de crisis". Index.comunicación, v. 5, n. 2, pp. 83-100.

http://journals.sfu.ca/indexcomunicacion/index.php/indexcomunicacion/article/view/167

Ortiz-de-Guinea, Yolanda; Villafañe, Justo; Caffarel-Serra, Carmen (2018). "Investigación para la evaluación de la reputación de los medios de comunicación". Revista latina de comunicación social, n. 73, pp. 845-869.

https://doi.org/10.4185/RLCS-2018-1285

Roses, Sergio; Farias-Batlle, Pedro (2012). "Credibilidad de los medios: un análisis bivariado de las opiniones de los españoles". Revista mediterránea de comunicación, v. 3, n. 1, pp. 79-104.

https://rua.ua.es/dspace/bitstream/10045/23080/1/ReMedCom_03_06.pdf

Roses, Sergio; Gómez-Calderón, Bernardo (2015). “Credibilidad de los medios en España: divergencias de percepción y caracterización de los escépticos". El profesional de la información, v. 24, n. 4, pp. 432-439.

https://doi.org/10.3145/epi.2015.jul.10

Tsfati, Yariv; Ariely, Gal (2014). "Individual and contextual correlates of trust in media across 44 countries". Communication research, v. 41, n. 6, pp. 760-782.

https://doi.org/10.1177/0093650213485972

Vila-López, Natalia; Küster-Boluda, Inés; Bigné-Alcañiz, Enrique (2012). “La televisión pública versus la privada ¿̇e perciben diferencias en calidad, identidad visual y reputación corporativa?" 3 ciencias. Revista de investigación, v. 1, n. 1, pp. 1-16.

https://www.3ciencias.com/wp-content/uploads/2013/04/2.-La-TV-pública-vs-privada.pdf

Villafañe, Justo (2004). La buena reputación. Claves del valor intangible de las empresas. Madrid: Pirámide. ISBN: 84 36818393

Warren, Carl (1979). Géneros periodísticos informativos. Nueva enciclopedia de la noticia. Barcelona: ATE. ISBN: 84850 47516

Yamamoto, Masahiro; Nah, Seungahn (2018). "A multilevel examination of local newspaper credibility". Journalism \& mass communication quarterly, v. 95, n.1, pp. 76-95.

https://doi.org/10.1177/1077699017721486

\section{Realiza tu proyecto}

Por una biblioteca pública social e inclusiva

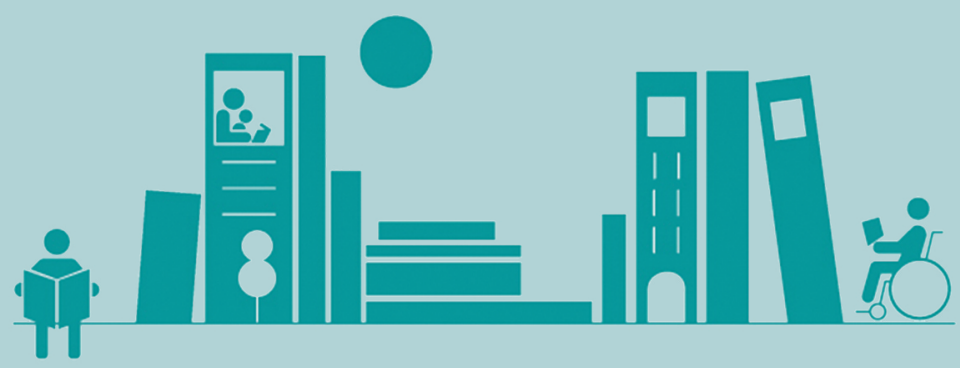

En nuestra web te ofrecemos unas pautas para facilitar la formulación de tu proyecto fundacionbibliotecasocial.org

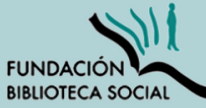
info@fundacionbibliotecasocial.org

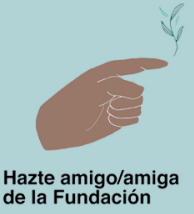

